\title{
Radical Group Degradation Study of Linear Low Density Polyethylene for Developing Environmentally Degradable Plastic Bags
}

\author{
Ruhul Amin M. ${ }^{1}$, Basel F. Abu-Sharkh ${ }^{2}$ and Mamdouh Al-Harthi ${ }^{2}$ \\ ${ }^{1}$ Department of Chemical Engineering \\ Bangladesh University of Engineering \& Technology (BUET), Dhaka-1000, Bangladesh \\ ${ }^{2}$ King Fahd University of Petroleum \& Minerals, \\ P. O. Box 5050 Dhahran 31261, Kingdom of Saudi Arabia
}

\begin{abstract}
We study the influence of adding three different type of additives on film grade polyethylene on the degradation behavior under natural weathering conditions in Saudi Arabia. Plastic films prepared by first premixing the film grade polyethylene pellets with different amounts of additives were exposed in outdoor environments located in Dhahran, Saudi Arabia. Original and degraded polymeric materials, as well as the relevant extractable fractions were characterized by FTIR. Carbonyl and double bond indexes were calculated on the basis of the relative intensities of the carbonyl band at $1715 \mathrm{~cm}^{-1}$ and the double-bond band at $1650 \mathrm{~cm}^{-1}$ to that of methylene scissoring band at $1465 \mathrm{~cm}^{-1}$, respectively. Comparison of different additives on the basis of degradation rate was determined and the additive PDQ shows the highest degradation rate at the amount of $10 \%$ mixing with Polyethylene.
\end{abstract}

Keywords: Degradation; polyethylene; additive; starch; polymer blends; FTIR; DSC

\section{Introduction}

The current huge global production of plastics has generated enormous environmental concerns, mainly related to the waste generation by plastic packaging, which are responsible for $35-40 \%$ share of annual plastics consumption ${ }^{1}$. Plastic bags and packaging account for a major part of our waste in landfills. More importantly, plastic bags are one of the top items of litter on our community beaches, roads, sidewalks, and vegetation along with cigarette butts and Styrofoam. Plastic bags are light and hard to contain. Because of their light weight, plastic bags fly easily in wind, float along readily in the currents of rivers and oceans, get tangled up in trees, fences, poles, and so forth, and block the grainage system.

Freedman $^{2}$ investigated the relation between the structure of additives (arylmethyl halides, phenacyl halides, haloalkenes) and their effectiveness in promoting photodegradation of polystyrene, polypropylene and polyethylene. Rodlan-Carrillo et al. ${ }^{3}$ studied starch metabolites and enzymes during starchbased plastic polymer biodegradation by the white rot fungus Phanerochaete chrysosporium, grown in sugarcane bagasse pith in tubular reactors.

Otto et al. ${ }^{4}$ investigated the biodegradability of 4 selected, compostable waste bag types in a respirometer test. The bags consisted of aliph.-arom. copolyester, starch/polycaprolactone and polyesteramide/ polycaprolactone.

Degradable bags can be classified in two ways according to their degradation mechanism: biodegradable, or require the action of heat, ultraviolet

* Corresponding Author: Ruhul Amin M

Email: amin@che.buet.ac.bd light, mechanical stress or water in order to degrade ${ }^{5}$. Photodegradation of poly (isobutylene oxide) was investigated by observing the degradation and photodegradation of the polymer observed ${ }^{6}$.

Scott reviewed different types plastics designed to undergo photodegradation, with discussions on mechanisms of degradation, current additives used to both prevent and enhance degradation, synergistic effects of certain additives, and how such additives impact on the useful lifetime of plastic products ${ }^{7}$. Hill reported fully degradable plastic bags from polyethene that contain a degradable compostable plastic additive technology that induces reduction of the plastic to carbon dioxide and water in just a few weeks ${ }^{8}$. The environmental degradation of polyethylene was reviewed by Hakkarainen \& Albertsson ${ }^{9}$. The thermal properties of a series of commercially degradable polymers were studied using thermogravimetry and differential scanning calorimetry by Day et al. ${ }^{10}$ Goheen et al. investigated low-density polyethylene films mixed with different percentages of corn starch which were exposed to soils and monitored for starch removal and chemical changes of the matrix using FTIR spectroscopy $^{11}$.

In this study, we investigate the degradation products and determine the time required to convert the material into gases or low molecular weight hydrocarbons. Plastic films were prepared by first premixing the film grade polyethylene pellets with different amounts of additives. The films were exposed in outdoor environments located in Dhahran, Saudi Arabia. Samples of the films were drawn at regular intervals and evaluated for degradation. 


\section{Experimental}

\section{Materials}

The film grade low density polyethylene obtained from SABIC, Saudi Arabia. In the experimental work, some additives were used to enhance photo-degradation. Three different type of photodegradable additives such as PDQ-H, Polystarch-N and Polystarch-Plus-H was supplied by Willow Ridge Co., USA.

\section{Sample Preparation}

Plastic films were prepared by first premixing the film grade polyethylene pellets with different amounts of additives. Additive loadings were 10, 20 and 30 percent mixed with pure polyethylene. Subsequently, the mixer was fed to an extruder to produces the film.

\section{Extrusion and Processing Condition}

The resulting "dry blend" was then extruded in a single screw extruder consisting of three heating sections and a die plate. The temperatures of the three heating zones of the barrel were set at $160^{\circ} \mathrm{C}$ and the temperature of the die section was set at $120^{\circ} \mathrm{C}$.

\section{Degradation Studies}

The degradability of the films in outdoor environment was determined in this study. The films were exposed in outdoor environments at the exposure site located in Dhahran, Saudi Arabia. The films were exposed for one year and samples were drawn at regular intervals and evaluated for degradation. Fig. 1 shows the photograph of the films at the time of exposure and Fig. 2 show the photographs of sample taken after 9 months.

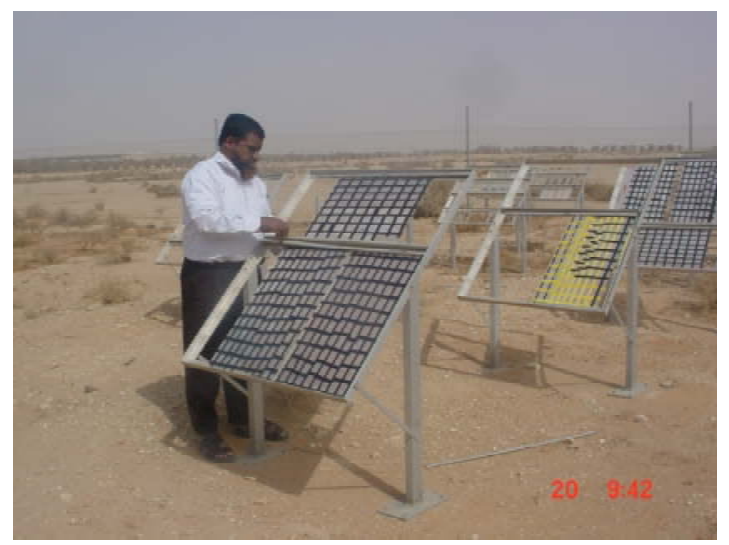

Fig.1. Exposing plastic samples in natural weathering condition. Films are fixed on plexy glasses and oriented in a steel rack at 45 degree angle with the basement and facing to east so that maximum amount of sunlight fall on the film in all time.

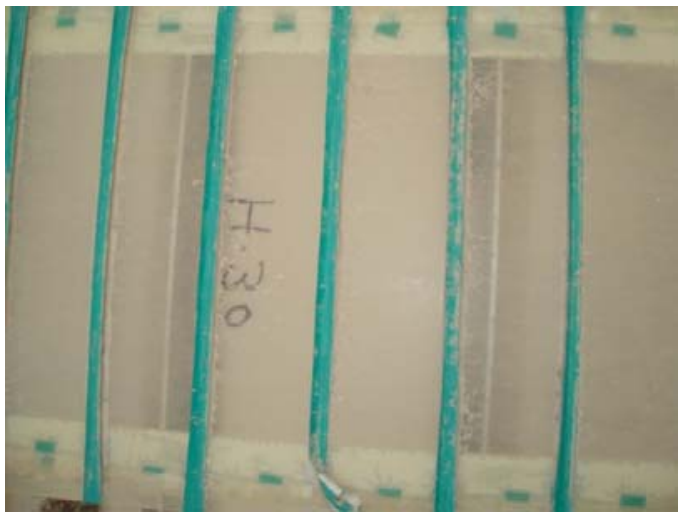

Fig.2. Photographs of sample containing 50 percent Polystarch-plus-H additive. It was taken after 9 months which shows that all the exposed parts were severely degraded and were taken away by air. Only small amount of sample which are attached by the tapes are left.

\section{Sample Analysis}

The IR Spectra of the samples retrieved from degradation experiments were recorded on a NicoletTM 6700 FT-IR spectrometer from a thermo-electron by using a smart orbit for net samples. The results were reported in wave numbers $(\mathrm{cm}-1)$ (Spectral resolution= $4 \mathrm{~cm}-1$; Number of scans, 4). Carbonyl and double bond indexes will be calculated on the basis of the relative intensities of the carbonyl band at $1715 \mathrm{~cm}^{-1}$ and the double-bond band at $1650 \mathrm{~cm}^{-1}$ to that of methylene scissoring band at $1465 \mathrm{~cm}^{-1}$, respectively.

\section{Results \& Discussion}

Fourier Transform Infra Red (FTIR) can be used as a powerful tool to detect structural changes such as an oxidation level of LDPE due to the UV-sunlight. Spectra FTIR, according to the time of ageing for the LLDPE and Polystarch N30 after different exposure days are given in the Fig. 4.

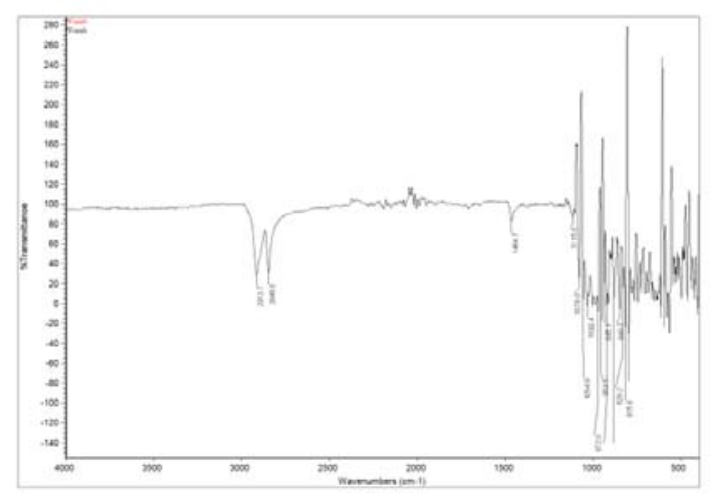

Fig.3. FTIR spectrum of Polyethylene 


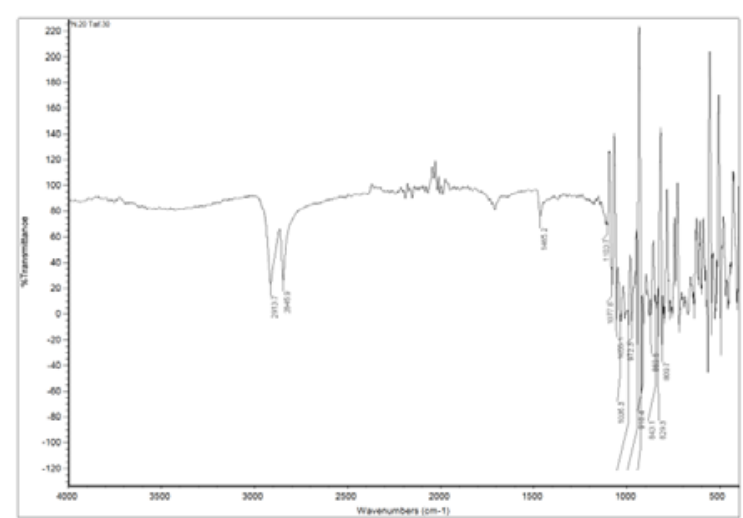

Fig.4. FTIR spectrum of $20 \%$ Polystarch N after 30 days

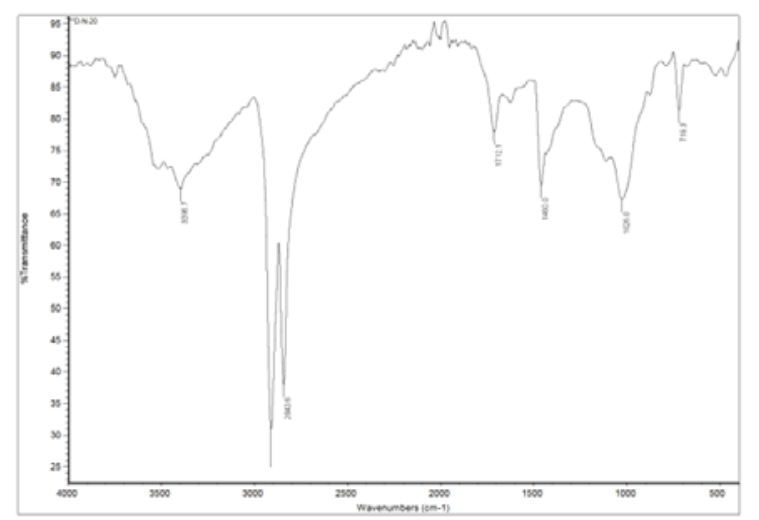

Fig.5. FTIR spectrum of $20 \%$ Polystarch N after 80 days

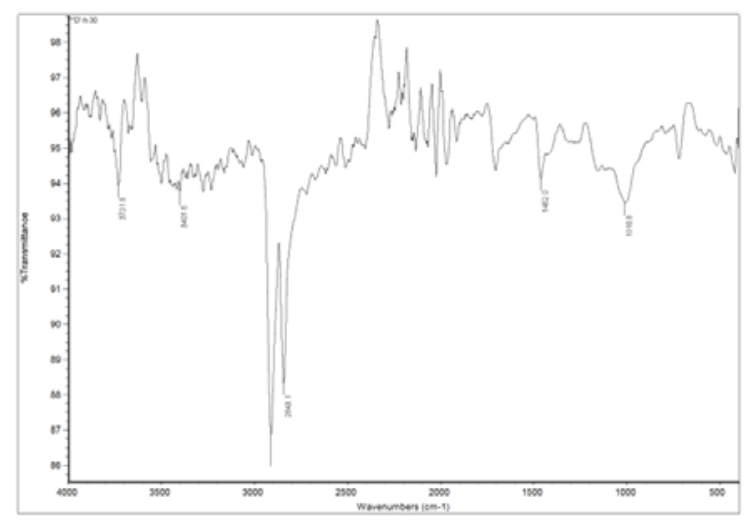

Fig.6. FTIR spectrum of 30\% Polystarch $\mathrm{H}$ after 95 days

The peaks at $1715 \mathrm{~cm}^{-1}$ shows the band vibration of the $\mathrm{C}=\mathrm{O}$ group which appears due to the photo-oxidation of the LLDPE. This band increases more considerably with the time.

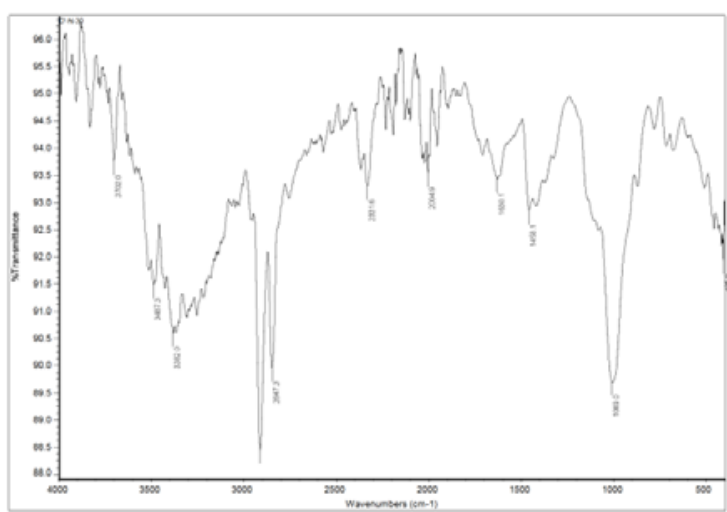

Fig.7. FTIR spectrum of $30 \%$ Polystarch N after 150 days

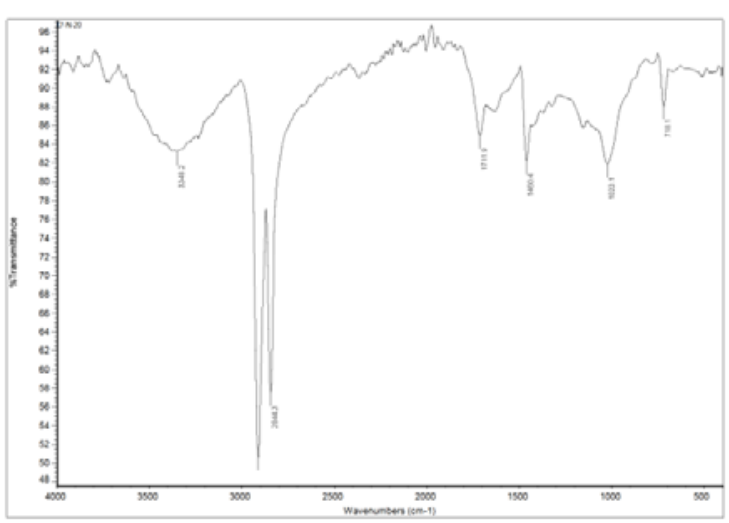

Fig.8. FTIR spectrum of $20 \%$ Polystarch N after 150 days

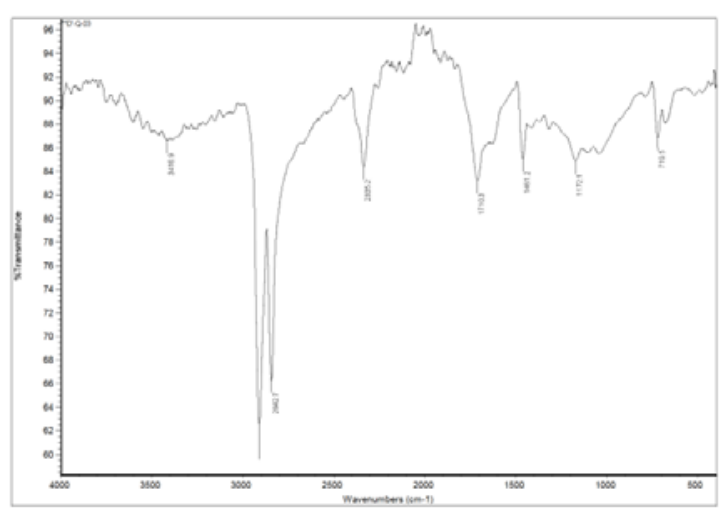

Fig.9. FTIR spectrum of 3\% PDQH after 150 days

The strong peak at $1715 \mathrm{~cm}^{-1}$ increases more considerably with the exposure time. This is because different types of radicals form on the film surface under the action of the light and/or heat can lead to reactions of reticulation of chains, reactions with oxygen in air and reactions of scission of chains [16]. 
The mechanism of degradation greatly depends on the nature and stability of the radical formed in the course of the reaction of photo-oxidation [17]. For LLDPE, stable radicals are formed due to tertiary carbons and these radicals propagate to react with other radicals causing reticulations of the chains. Very reactive radicals are formed due to the secondary carbons of LDPE which cause reactions of chains scission [18]. From the experiment, it was found that the additive Polystarch-N shows the highest degradation rate compared to other additives. PDQ-H is the second and Polystarch-H shows the lowest degradation behavior.

\section{Conclusion}

1. All the samples showed the degradation behaviour, specially samples blended with PDQH additive showed severe degradation.

2. The samples exposed for 4 months showed cracked, fractured big pits which indicate severe photodegradation and will be converted to powder soon as compared to the samples exposed for 30 days only.

3. The photographs taken after 9 months shows that all the exposed parts are severely degraded and are taken away by air. Only the portions which are attached by the tapes are left.

4. The additive PDQ shows that highest degradation rate at the amount of $10 \%$ mixing with Polyethylene.

\section{Acknowledgements}

This work was funded by King Abdul Aziz City for Science and Technology (KACST) (Grant Number:7925).

\section{References}

1. Miertus, Stanislav; Ren, Xin. (2002) "Environmentally degradable plastics and waste management" International Centre for Science and High Technology (ICS-UNIDO), Trieste, Italy. Polimery (Warsaw, Poland),47(7/8), 545-550.

2. Freedman, Bernard, "Photodegradable vinyl plastics. (1976), II. Effect of arylmethyl halides, phenyl halomethyl ketones and haloalkene additives". Journal of Applied Polymer Science 20(4), 911-19.

3. Roldan-Carrillo T; Rodriguez-Vazquez R; DiazCervantes D; Vazquez-Torres H; Manzur-Guzman A; Torres-Dominguez A (2003) "Starch-based plastic polymer degradation by the white rot fungus Phanerochaete chrysosporium grown on sugarcane bagasse pith: enzyme production, Bioresource technology 86(1), 1-5.

4. Otto, Simone; Borg, Heinz; Jank, Manfred;
Schnabel, Rainer; Jabusch, Roman. (2003), "Laboratory studies on the biodegradation of compostable waste bags. Muell und Abfall 35(9), 484-488.

5. ExcelPlas (2003) "The impacts of degradable plastic bags in Australia", Final Report to Department of the Environment and Heritage, Australia, Centre for Design at RMIT, Nolan-ITU, September.

6. Lee, Yoon Bae; Choi, Jeong Hyun. (1997) Synthesis and degradation mechanism of poly(isobutylene oxide). Pollimo (1997), 21(6), 961-965.

7. Scott, Gerald., (1990) Polymers with enhanced photodegradability. Journal of Photochemistry and Photobiology, A: Chemistry 51(1), 73-9

8. Hill, Steve. (1999), "Plastics refuse to degrade quickly". Materials World, UK. Materials World 7(3), 135-136.

9. Hakkarainen, Minna; Albertsson, Ann-Christine. (2004), "Environmental degradation of polyethylene". Advances in Polymer Science 169(Long-Term Properties of Polyolefins), 177199.

10. Day, M.; Cooney, J. D.; Shaw, K.; Watts, J. (1998), "Thermal analysis of some environmentally degradable polymers". Journal of Thermal Analysis and Calorimetry 52(2), 261-274.

11. Goheen, S. M.; Wool, R. P. J Appl Polym Sci 2003, 42, 2691.

12. Gisjsman P, Sampers J. The influence of oxygen pressure and temperature on the UV-degradation chemistry of polyethylene. Polym Degrad Stab 1997;58:55-9.

13. Allen NS, Adge M, Houldsworth D, Rahman A, Catalina F, Fontan E, et al. Ageing and spectroscopic properties of polyethylenes: comparison with metallocene polymer. Polym Degrad Stab 2000;67:57-67.

14. Tidjani A. Comparison of formation of oxidation products during photooxidation of linear low density polyethylene under different natural and accelerated weathering conditions. Polym Degrad Stab 2000;68:465-9.

15. Gulmine JV, Janissek PR, Heise HM, Akcelrud L. Degradation profile of polyethylene after artificial accelerated weathering. Polym Degrad Stab 2003;79:385-97.

16. Abdelkader Dehbi a,b,*, Amar Bouaza a, Ahmed Hamou b, Boulos Youssef c, Jean Marc Saiter c Materials and Design 31 (2010) 864-869.

17. Hanafi A, Paposolomontos A. Integrated production and protection under protected cultivation in the Mediterranean region. Biotechnol Adv 1999;17: 183-203.

18. Briassoulis D. Mechanical behavior of biodegradable agricultural films under real field conditions. Polym Degrad Stab 2006;91:1256-72. 